\title{
Postgraduate peer tutors supporting academic skills in online programmes
}

\section{Sharon Boyd}

The Royal (Dick) School of Veterinary Studies, The University of Edinburgh, UK Jessie Paterson

The Royal (Dick) School of Veterinary Studies, The University of Edinburgh, UK

\begin{abstract}
This case study presents an evaluation of an online, distance-learning, postgraduate peer tutor project, covering the pilot and post-pilot years 2013-15. The project has two core aims: first, to develop student academic skills in group facilitation and learning support; second, to enhance support for increasing numbers of online, distance-learning students by facilitating more live sessions and providing postgraduate study advice. Feedback from staff, peer tutors and the students involved suggests that peer tutoring is successful in improving distance learners' experience through enhanced support and fostering a sense of community; for the peer tutors, the opportunities to develop graduate skills in tutoring and collaborating as part of the academic community.
\end{abstract}

Keywords: peer support; online learning; distance learning; postgraduate; student experience.

\section{Introduction}

Working online at distance can be isolating due to the perceived separation between student and teacher (Falloon, 2011). Delahunty et al. (2014) outline the 'socio-emotional challenges' inherent in engaging online distance learning (ODL) students, such as a sense of isolation and reduced confidence. Key to this is the recognition of the diversity of online learners and therefore the need to facilitate a variety of opportunities for them to interact and build a sense of community and connectedness. Increasing ODL student numbers 
places a strain on student support services (Reid et al., 2014), potentially increasing the sense of isolation due to delays in response and reduced tutor 'presence'. Watts et al. (2015) report that online Peer-Assisted Learning (PAL) or peer-supported learning activities may assist in dealing with these issues.

Peer support and group assessment activities are core within postgraduate taught (PGT) ODL courses at the Royal (Dick) School of Veterinary Studies [R(D)SVS], University of Edinburgh. When students start, they are encouraged to take an active role in asynchronous discussion boards and synchronous seminars as part of course content and delivery. This allows students to develop core graduate attribute skills in group facilitation, debate and dialogic feedback. Guidance is provided and students are shown how these activities enhance the social and 'collegial' networks (McLuckie and Topping, 2004) constructed as part of their participation on a chosen programme of study. This social constructivist model follows Weller (2007), seeking a 'balance of people, process, and technology' (p.157), building the learning community by providing clear guidance, accessible systems, and encouraging ongoing dialogue.

The same pedagogical approach is extended to peer tutor (PT) training, allowing PTs to further develop skills in discussion with the academic training team. The PT role is key in building this community of practice, as PTs support the learning of others within the community, what Ashwin (2003) calls a 'peer supporter'. As PTs have progressed further in their programme, they can share a wider range of experience than peers on the same course. Since they come from outside the course, students view them as occupying a separate role, or higher level, from their own, situated between the role of 'student' and 'teacher'. PTs assist with community development by providing a relaxed supportive environment and safe space to ask questions without the concern of appearing 'stupid' in front of an academic specialist (McLuckie and Topping, 2004). The PT role is seen as motivating, both in supporting peers' development and in inspiring students to undertake the PT role themselves.

\section{Purpose of the work}

The aims of the project are two-fold: first, to develop PTs' tutoring skills as part of their portfolio of academic skills; and second, to provide additional support to ODL students. To 
achieve the first aim, guidance focuses on online facilitation in both asynchronous (discussion board) and synchronous (real-time study group) activities. PTs have access to information on academic skills support, including critical reading, writing, information skills, basic data handling, and presentation skills. Additional support and advice on time management and session planning are also given. The second aim focuses on shared peer experience and increased connectedness through providing additional live group sessions across time zones facilitated by peers. Feedback is gathered from a number of sources including course surveys, PT focus groups and staff-student meetings. This data is reviewed by the authors to gain an overview of the project, highlight benefits to students and programme teams, and identify areas requiring improvement as part of the postgraduate teaching review process.

\section{Participants}

Approximately 350 students are registered for flexible, part-time, PGT ODL programmes at the $R(D) S V S$. The part-time programmes last between two and six years. Most students opt for the three years; two years of taught materials and a one-year dissertation project. Most students, including PTs, are in full- or part-time employment.

These programmes cover a range of specialist areas, including conservation medicine, international animal welfare, equine science and one health. Students have biological and veterinary science undergraduate degrees, and network within a global peer group from locations including the UK, US, Central and South America, Canada, Europe, Australia, and the Middle and Far East.

An invitation was sent to all ODL PGT students in the summer of 2013 and 2014. It is a pre-requisite to have successfully completed either the Scientific Methodology course which is offered as part of some MSc programmes, or the Academic Skills course which is optional for all PGT students. Both courses provide guidance on academic skills development. The assessments require students to critically reflect on their own learning development. Unlike Beaumont et al. (2012), PT familiarity with online communication tools was not a selection criterion, as all PGT ODL students are familiar with a range of standard tools used as part of their studies. 
In both pilot and post-pilot phase, PTs are made aware that active input through de-brief and focus group sessions is an essential element of the role. These group discussions and feedback provide benefits both to the PT in the forms of autonomy and motivation, and the training team in developing a student-led initiative. PTs can withdraw at any point and are reminded that the role should not conflict with their studies.

\section{Pilot phase (2013-14)}

Six PTs underwent training in 2013-14 from a range of programmes. Two had completed and were awaiting graduation in November 2013, two were in second year, and two were in third (dissertation) year.

\section{Post-pilot phase (2014-15)}

Eight PTs underwent training in 2014-15, four new and four returning, again from a range of programmes. Of the new PTs, one had completed was awaiting graduation in November 2014, two were in second year, and one was in third (dissertation) year. Of the returning PTs (trained the previous year), two had completed and were awaiting graduation, and two were in third (dissertation) year.

\section{Role of PT}

PTs can tutor a maximum of three courses per year, with most opting for two. Taking a similar approach to Baran and Correia (2009), PTs are required to:

- Complete the training course ( 15 hours).

- Attend debriefing sessions (4 hours).

- Liaise with course teams on logistics (such as synchronous session timings, identification of skills required for assessment topic) ( 2 hours).

- Facilitate asynchronous discussions sharing experiences and skills (2 hours per course at peak pre-assessment times).

- Run synchronous sessions focusing on a particular academic skill topic, for example, critical writing (two 1-hour group sessions per course, 3 hours preparation time per session). 
- Reflect on practice ( 7 hours), demonstrated through critical consideration of what worked well or what required refinement in preparation for next tutoring session. This is facilitated through discussion with the training team via discussion board and de-brief sessions, and through student application for Associate Fellowship of the Higher Education Academy.

PTs are advised that the role involves tutoring core academic skills (McLuckie and Topping, 2004; Baran and Correia, 2009) rather than subject-specific teaching, in part to deflect concerns about having sufficient experience to 'teach' their peers (Lachman et al., 2013). PTs appreciate how the process of facilitation invites group discussion and sharing of experience leading to 'reflective knowledge building' (Roscoe and Chi, 2007), rather than expectation of mastery in a given area.

\section{PT Training}

PTs have access to a peer-tutor training course on the university's virtual learning environment (Blackboard Learn). The structure models the University of Manchester (2014) PASS (peer-assisted study session) format that is used successfully with our undergraduate on-campus groups. PTs work in pairs to support each other and share preparation work for live sessions. The training facilitates partnership building in advance of tutoring.

The training course has three components:

- Key skills such as group facilitation techniques, confidentiality, support.

- Guidance for tutoring online (course materials for self-study, discussion and training in facilitating online group communication).

- Practice sessions ( 20 minutes with training staff and other PTs acting as students).

The aim is to provide multimodal training as per De Smet et al. (2010). PTs are trained in online moderating following Salmon's (2012; 2013) five-stage model through live sessions with the training staff and asynchronous discussions on topics such as ice-breakers, 'lurkers' and community building. They are provided with examples and guidance on the communication tools commonly used with the student group, which are Skype (text chat) 
or Blackboard Collaborate (virtual classroom). Having selected their preferred tool for synchronous group meetings, they run mock sessions to practice and gain feedback from the group, also proposed in Galbraith and Winterbottom (2011). In response to PT request, further detail on assessment types are provided with an outline of core skills expected of students.

In the pilot, PTs tutored on the Academic Skills course, which acts as a support 'centre' for postgraduate study skills, similar to Reid et al. (2014). All ODL PGT students are registered. This course was selected as it matches the core aim of the PT role and the authors are also the course team. This ensured closer monitoring and support during the pilot.

Students self-register for live sessions at times chosen by PTs; a member of the training team monitors e-mail in case of technical difficulty. While not often required, this acts as a safety net; PTs know help is available should they or the attendees encounter problems.

In the post-pilot, the PT role has been integrated within core PGT courses. The role remains the same - synchronous and asynchronous sessions at times agreed by course teams and PTs. Due to the small number of PTs relative to courses, PTs are invited to select their preferred course(s) to tutor. The training team assist PTs with any queries on running live sessions or additional study skills guidance. This minimises impact on course teams whilst ensuring PTs feel supported.

\section{Methodology}

Data were collected using a mixture of focus group (PTs and course staff) and surveys (students). Data triangulation is achieved through consideration of the views of PTs, staff and students, and the mixed methods approach of feedback via multiple routes.

To date, four PT focus groups have been facilitated via Skype by a member of staff not involved with PT training or online teaching. A minimum of two and a maximum of four PTs attended each focus group. The facilitator anonymised the Skype transcripts before sharing with the authors, and all three analysed the transcripts in isolation before comparing themes identified. The authors also reviewed transcripts and recordings of live 
sessions, providing feedback in de-briefings with PTs and via e-mail to further develop teaching skills.

Low response to course surveys (<12\%, 2-6 students per course) made statistical analysis unfeasible. Further input was gathered through the staff-student liaison committee meetings. The College Educational Research Ethics Committee granted approval to carry out this research.

\section{Findings and impact}

\section{Pilot year (2013-14)}

There were positive responses from PTs and students attending sessions in the Academic Skills course. In the focus group, all six PTs said they trained in order to make a contribution/give something back:

Having spent 3 years as a distance learning student I wanted to contribute something that would help other students in the future by sharing own experiences.

This was achieved through shared experience with students and staff:

It was satisfying hearing that the students had learned something that would help them to improve their academic skills and hopefully improve their grades... I enjoyed liasing [sic] with the course lecturers in order to work out how best to support them.

PTs also recognised the importance of supporting new and/or mature students:

I've also been out of academia for a long time myself, so think I can empathise easily with anyone struggling with academic study skills.

There was also the added benefit of improving personal skills:

I also wanted to improve my own skills and keep myself updated. 
PTs all agreed working in pairs guaranteed smoother facilitation, as both live session methods needed more than one person to monitor fast-moving text chat and ensure all questions were answered.

Issues reported:

- Timing of sessions (conflict with core courses).

- High number of PTs in one course (conflict with PT preferred times).

- Low attendance (again due to conflict with core courses).

These issues were resolved in the post-pilot by embedding PTs in core courses.

\section{Post-pilot year (2014-15)}

Positive responses were received from PTs and students. PT reasons for taking on the role matched the previous year, as four of the eight PTs were tutoring for their second time.

Students report that having PTs on their courses is very encouraging, as PTs understand the constraints of studying part-time at distance. PT sessions were:

Very helpful. Nice and informal. Comforting to be able to share experience, opinions, thoughts with students who have been through it before. (Student feedback via staff student liaison committee meeting)

In course feedback, students agree or strongly agree that having PT-run study sessions is helpful (11\% response rate, 39 of 353$)$. The provision of recordings/transcripts and asynchronous discussion board monitoring ensures that students who cannot attend are not excluded.

Course teams agree that PT presence enhances the student learning experience by providing an increased sense of support and community. While it is not possible to say if PT presence has a significantly positive effect on results, extra support is viewed as beneficial. No difference is observed in support provided by PTs tutoring on courses different from their programme specialism. 
An approval system will be put in place following the recommendation that PT applicants have official approval of their programme team when applying. The primary method of student volunteering for training will be maintained to ensure students are self-motivated and have sufficient time to meet role requirements. Programme leaders will also recommend dissertation students consider this voluntary role to combat feelings of isolation reported while working on research.

\section{Discussion}

Positive feedback from staff, PTs and students involved indicates the scheme is successful. Due to the structure of the programmes, there is no method to accurately determine if PT presence improves grades. However, staff and students indicate improved student experience through enhanced support. Live-session attendance increased in the post-pilot phase due to the change in the mode of delivery. Although attendance was still low $(<5)$ for some sessions, PTs and students reported benefits from discussion.

As reported by Watts et al. (2015), low attendance rates can be caused by a number of factors. Some can be resolved, for example, live session scheduling to avoid timetable clashes. A key factor appears to be lack of student recognition of the need for peer support. Staff report that some assessment feedback touches on topics which have been covered in PT sessions which the student in question chose not to attend.

The choice of live-session tool appears to influence the PT tutoring style in this case. Those using text-chat demonstrate a more social-constructivist approach, facilitating open group discussion with guiding questions. Those using the virtual classroom take a marginally more instructivist, 'knowledge-telling' (Berghmans et al., 2013) approach giving a presentation and inviting questions at the end. It could be argued that confidence influences the activity. PTs choosing to use Skype do so as there are potentially less technical difficulties (technical confidence). Of those choosing Collaborate, some use the method they are familiar with through giving presentations on their research as part of their assessed work (method confidence). Those with more technical and pedagogical confidence (tutoring their second year and/or drawing on professional teaching experience) choose to 'flip' the classroom with recorded presentations and questions on 
the discussion board, or create more interactive sessions by making more active use of questions and the whiteboard facility.

Further research is required, particularly into role perceptions (Roscoe and Chi, 2007), as this can influence tutoring behaviours. PT pairs may facilitate peer monitoring as per Berghmans et al. (2013), encouraging PTs to enhance their approach by adopting strategies demonstrated successfully by their partners, or other PTs.

Due to small numbers involved in the project to date, it has not been possible to carry out the linguistic analysis methods suggested by Watts et al. (2015). This may be an option going forward to assist in researching the process in more depth.

\section{Conclusion}

As recognised in Delahunty et al. (2014), students appreciate a variety of opportunities to connect with the course team. PTs can play a key role in enhancing student experience, reducing feelings of isolation (Baran and Correia, 2009) through social learning practices (Ashwin, 2003). Students respond positively to support provided by PTs, finding peer-led sessions a relaxed space to ask questions. In this, we see the 'trusting relationship' described by McLuckie and Topping (2004), where students discuss items they find confusing with a peer, i.e. someone not in a position of authority.

PTs report that the training course provides opportunities to develop their understanding, confidence and skills in facilitating online. It acts as a support area to raise issues, ask questions and connect with PT and academic colleagues separate from the students being peer-tutored - another aspect of the trusting relationship essential for sharing concerns.

As reported by Watts et al. (2015), it can be difficult to identify what elements constitute a successful peer project. A positive outcome is seen in the increased numbers of students actively requesting the role of peer tutor this year having been inspired by the example of their tutors in previous years. 


\section{Acknowledgements}

The postgraduate peer tutor project was supported by funding from the Institute for Academic Development, the College of Medicine and Veterinary Medicine and the Royal (Dick) School of Veterinary Studies, University of Edinburgh. The authors would like to thank the peer tutors, colleagues from the Veterinary Medical Education section, and the Institute for Academic Development for their participation and guidance in the project.

\section{References}

Ashwin, P. (2003) 'Peer facilitation and how it contributes to the development of a more social view of learning', Research in Post-Compulsory Education, 8(1), pp. 5-18. DOI: $10.1080 / 13596740300200137$.

Baran, E. and Correia, A.P. (2009) 'Student-led facilitation strategies in online discussions', Distance Education, 30(3), pp. 339-361. DOI: $10.1080 / 01587910903236510$.

Beaumont, T.J., Mannion, A.P. and Shen, B.O. (2012) 'From the campus to the cloud: the Online Peer Assisted Learning Scheme', Journal of Peer Learning, 5(1), pp. 1-15 [Online]. Available at: http://ro.uow.edu.au/ajpl/vol5/iss1/6/ (Accessed: 8 June 2015).

Berghmans, I., Neckebroeck, F., Dochy, F. and Struyven, K. (2013) 'A typology of approaches to peer tutoring. Unraveling peer tutors' behavioural strategies', European Journal of Psychology of Education, 28(3), pp. 703-723. DOI: 10.1007/s10212-012-0136-3.

Delahunty, J., Verenikina, I. and Jones, P. (2014) 'Socio-emotional connections: identity, belonging and learning in online interactions. A literature review', Technology, Pedagogy and Education, 23(2), pp. 243-265. DOI:

10.1080/1475939X.2013.813405. 
De Smet, M., Van Keer, H., De Wever, B. and Valcke, M. (2010) 'Cross-age peer tutors in asynchronous discussion groups: exploring the impact of three types of tutor training on patterns in tutor support and on tutor characteristics', Computers \& Education, 54(4), pp. 1167-1181. DOI: 10.1016/j.compedu.2009.11.002.

Falloon, G. (2011) 'Making the connection', Journal of Research on Technology in Education, 43(3), pp. 187-209, DOI: 10.1080/15391523.2011.10782569.

Galbraith, J. and Winterbottom, M. (2011) 'Peer-tutoring: what's in it for the tutor?', Educational Studies, 37(3), pp. 321-332. DOI: 10.1080/03055698.2010.506330

Lachman, N., Christensen, K.N. and Pawlina, W. (2013) 'Anatomy teaching assistants: facilitating teaching skills for medical students through apprenticeship and mentoring', Medical Teacher, 35(1), e919-e925. DOI: 10.3109/0142159X.2012.714880.

McLuckie, J. and Topping, K.J. (2004) 'Transferable skills for online peer learning', Assessment \& Evaluation in Higher Education, 29(5), 563-584. DOI: 10.1080/02602930410001689144.

Reid, M., Shahabudin, K. and Hood, S. (2014) 'Case study: the 24/7 study advice workshop', Journal of Learning Development in Higher Education, Special Edition: Digital Technologies in Learning Development, November, pp. 1-12 [Online]. Available at:

http://www.aldinhe.ac.uk/ojs/index.php?journal=jldhe\&page=article\&op=view\&pat $\underline{\mathrm{h} \% 5 \mathrm{~B} \% 5 \mathrm{D}=270}$ (Accessed: 8 June 2015).

Roscoe, R.D. and Chi, M.T. (2007) 'Understanding tutor learning: knowledge-building and knowledge-telling in peer tutors' explanations and questions', Review of Educational Research, 77(4), pp. 534-574. DOI: 10.3102/0034654307309920.

Salmon, G. (2012) E-moderating: the key to online teaching and learning. New York: Routledge. 
Salmon, G. (2013) E-tivities: the key to active online learning. New York: Routledge.

University of Manchester (2014) About PASS. Available at:

http://www.pass.manchester.ac.uk/about-pass/ (Accessed: 8 May 2015)

Watts, H., Malliris, M. and Billingham, O. (2015) 'Online peer assisted learning: reporting on practice', Journal of Peer Learning, 8, pp. 85-104 [Online].

Available at: http://ro.uow.edu.au/ajpl/vol8/iss1/8 (Accessed: 6 October 2015)

Weller, M. (2007) 'The distance from isolation: why communities are the logical conclusion in e-learning', Computers \& Education, 49(2), pp. 148-159. DOI:

10.1016/j.compedu.2005.04.015.

\section{Author details}

Sharon Boyd is a Lecturer in Distance Student Learning at the Royal (Dick) School of Veterinary Studies. She joined the R(D)SVS in 2007 as programme coordinator of online postgraduate and continuing professional development (CPD) courses. In 2013, she took on the role of Director of the postgraduate Certificate in Advanced Veterinary Practice programme, and is programme coordinator for a new veterinary MSc programme in Advanced Clinical Practice. Her remit includes study skills support for postgraduate students working online at distance, and her research areas of interest include distance and sustainable education. She is course leader for the postgraduate Academic Study Skills course and co-lead on the online postgraduate peer tutor scheme, based on the undergraduate VetPALs model.

Jessie Paterson is a Lecturer in Student Learning at the Royal (Dick) School of Veterinary Studies. As well as teaching on the School's Professional Skills course, she is an active member of the School's Student Undergraduate Support Team. Her particular remit is study skills and she leads the School Team dedicated to providing study skills support to the vet students. In 2013, she led and piloted a successful undergraduate peer assisted learning scheme, VetPALs, and this has become a key component of the first year undergraduate student experience. She was also a co-lead in a scheme for online distance students based on this model. 